\title{
INTRODUCTION
}

\section{Diagnosis and Treatment of Dementia: the Fourth Canadian Consensus Conference}

\section{Christopher Patterson*1 and Serge Gauthier ${ }^{2}$}

It is inevitable that when discoveries are made in any medical field there is pressure to move expeditiously to clinical applications of these discoveries. While there is every reason to disseminate widely the results of efficacious therapeutic trials that improve meaningful clinical outcomes, and diagnostic strategies that are more sensitive, more specific, less burdensome to the patient and more parsimonious of resources, some restraint is advisable when the benefits are less compelling. For example, a technique that allows an earlier diagnosis of an incurable disease - such as Alzheimer's disease (AD) - risks labeling an individual, affecting the person's ability to acquire life, health or travel insurance, and may result in suspension of driving privileges.

Finding the balance between embracing leading-edge technologies prematurely and failing to accept proven therapies or diagnostic strategies in a timely manner is the sweet spot to which we should all aspire. We must try to avoid repeating the unfortunate experiences occasioned by widespread prescription of medications before the true range of adverse effects has been elucidated (for example, rofecoxib), by surgical procedures of dubious value (for example, external carotid artery to internal carotid artery bypass) as much as by laggardly adoption of effective treatments such as thrombolysis in stroke and myocardial infarction.

While we all depend upon evidence to guide our decision-making, it is regrettable for many of our clinical dilemmas that high-quality evidence is in short supply. Members of the Fourth Canadian Consensus Conference on the Diagnosis and Treatment of Dementia (CCCDTD4) have tried to find this balance, by carefully examining the available evidence, formulating recommendations, seeking peer review and eventually reaching consensus (mostly) on final recommendations to clinicians and, in some cases, investigators. This CCCDTD4 build upon the three previous conferences [1-3] but has important differences.

*Correspondence: pattec@hhsc.ca

'Hamilton Health Sciences, Department of Medicine, Faculty of Health Sciences,

Mcmaster University, St Peter's Site, 88 Mapleview Avenue, Hamilton, Ontario,

Canada L8M 1W9

Full list of author information is available at the end of the article
First, we targeted clinicians who are nondementologist specialists, notably general neurologists, internists, geriatricians and general psychiatrists. Our secondary audience was primary care practitioners, who in Canada are mostly family physicians.

Second, we endeavored to fulfill the tenets of the Appraisal of Guidelines for Research and Evaluation Collaboration, a list of criteria designed to improve the methodological quality of the exercise [4]. Twenty out of 23 criteria were met.

Third, we planned for dissemination and knowledge exchange well in advance, so that all recommendations were published relatively soon after the conference $[5,6]$, and the Canadian Dementia Knowledge Translation Network mounted a strategy to reach practitioners, lay public and policy-makers [7]. In addition, a commercial Internet-based educational initiative was launched [8]. Representation of membership was broad, and for the first time included a bioethics consultant and a consumer. The whole initiative was supported by funds independent of any commercial interest. To support each recommendation, background papers were prepared for each topic group. These papers are included in the Canadian Consensus Conference supplement published in Alzheimer's Research \& Therapy.

Many changes to the diagnostic criteria for the dementias and prodromal conditions have been advanced in recent years. The definitions group recommended the adoption of the diagnostic criteria of the National Institute on Aging-Alzheimer's Association Working Group for dementia, probable and possible AD and mild cognitive impairment due to AD [9]. There was considerable discussion and concern about the concept of prodromal $\mathrm{AD}$ based on biomarkers, and the concept should be reassessed when prognostic validation has been established.

The neuroimaging group engaged in a comprehensive review of existing and developing technologies $[10,11]$. Despite the extremely promising nature of amyloid imaging, the group advised against widespread clinical adoption of this modality until its role in diagnosis and prognosis can be more fully understood. Amyloid imaging use in cognitively normal individuals is particularly fraught with ethical and practical hazards. Recommendations 
about directions for future research in magnetic resonance imaging (functional magnetic resonance imaging, magnetic resonance spectroscopy, and so forth) and amyloid imaging will be explained in a subsequent article.

The pharmacology group reported that while there have been no new cognitive enhancing pharmacological agents approved for use since the last consensus conference, the role of cholinesterase inhibitors in severe AD and dementia associated with Parkinson's disease is now established. Recognizing the increased incidence of strokes and all-cause mortality associated with antipsychotic medications in people with dementia, recommendations are made based on the balance of risks and benefits to the individual or others [12].

We hope that the results of our deliberations will be of interest to the international community, for dementias of all types will challenge patients, caregivers and the healthcare systems, not only in Canada but throughout the developed and developing world.

\section{Abbreviations}

AD, Alzheimer's disease; CCCDTD4, Fourth Canadian Consensus Conference on the Diagnosis and Treatment of Dementia.

\section{Competing interests}

The authors declare that they have no competing interests.

\section{Acknowledgements}

The steering committee of the CCCDTD4 was: Howard Chertkow, Serge Gauthier (Co-Chair), Michael Gordon, Nathan Herrmann, Christopher Patterson (Co-Chair), Kenneth Rockwood, Pedro Rosa-Neto, and Jean-Paul Soucy. Authorship of the steering committee is recognized in $[5,6]$. Funding support had been provided for knowledge translation in the Third Canadian Consensus Conference in 2006, but had not been fully expended. These residual funds were adequate to cover the costs of the present CCCDTD4 Although the original source of these funds had included pharmaceutical companies, the temporal separation and intended use insured that there was no commercial influence in the selection of participants, choice of topics, and preparation of background papers or recommendations. In-kind support was also provided by the Canadian Dementia Knowledge Translation Network (supported by the Canadian Institutes of Health Research), and the offices of Dr Serge Gauthier (McGill University), Dr Christopher Patterson (McMaster University) and Dr Howard Chertkow (McGill University). The website, including online voting, was maintained by Medplan Inc.

\section{Declarations}

This article has been published as part of Alzheimer's Research \& Therapy Volume 5 Supplement 1, 2013: Background documents to the 4th Canadian Consensus Conference on the Diagnosis and Treatment of Dementia (CCCDTD4). The full contents of the supplement are available online at http://alzres.com/supplements/5/S1.

Publication charges for the supplement were funded by the Canadian Consensus Conference on the Diagnosis and Treatment of Dementia (CCCDTD). Although residual conference funds used include contributions from pharmaceutical companies, no commercial organization has been involved in the selection of participants, choice of topics, preparation of background papers or recommendations. In kind support was also provided by the Canadian Dementia Knowledge Translation Network, and the offices of Drs Serge Gauthier (McGill University), Christopher Patterson (McMaster University) and Howard Chertkow (McGill University), whose role as Guest Editors involved the coordination of the project without involvement in the journal's standard peer review process which applied for all articles.

\section{Author details}

'Hamilton Health Sciences, Department of Medicine, Faculty of Health Sciences, Mcmaster University, St Peter's Site, 88 Mapleview Avenue, Hamilton, Ontario, Canada L8M 1W9. ${ }^{2}$ The McGill Center for Studies in Aging, 6825 LaSalle Boulevard, Montreal, QC, Canada H4H 1 R3.

Published: 8 July 2013

\section{References}

1. Assessing dementia: the Canadian Consensus. Organizing Committee Canadian Consensus Conference on the Assessment of Dementia. CMAJ 1991, 144:851-853.

2. Patterson C, Gauthier S, Bergman H, Cohen CA, Feightner JW, Feldman H, Hogan DB: The recognition, assessment and management of dementing disorders: conclusions from the Canadian Consensus Conference on Dementia. CMAJ 1999, 160(Suppl):S1-S15.

3. Chertkow H: Diagnosis and treatment of dementia: introduction. CMAJ 2008, 178:316-321.

4. The AGREE Collaboration: Development and validation of an international appraisal instrument for assessing the quality of clinical practice guidelines: the AGREE project. Qual Saf Health Care 2003, 12:18-23.

5. Gauthier S, Patterson C, Chertkow H, Gordon M, Herrmann N, Rockwood K, Rosa-Neto P, Soucy JP; CCCDTD4 Participants: Recommendations of the $4^{\text {th }}$ Canadian Consensus Conference on the Diagnosis and Treatment of Dementia (CCCDTD4). Can Geriatr J 2012, 15:120-126.

6. Gauthier S, Patterson C, Chertkow H, Gordon M, Herrmann N, Rockwood K, Rosa-Neto P, Soucy JP; CCCDTD4 Participants: 4th Canadian Consensus Conference on the Diagnosis and Treatment of Dementia. Can J Neurol Sci 2012, 39(6 Suppl 5):S1-S8.

7. Canadian Dementia Knowledge Translation Network [www.lifeandminds.ca]

8. Gordon M: What's New from the Canadian Consensus Conference on the Diagnosis and Treatment of Dementia (CCCDTD4) [www.healthplexus.net]

9. McKhann GM, Knopman DS, Chertkow H, Hyman BT, Jack CR Jr, Kawas CH, Klunk WE, Koroshetz WJ, Manly J, Mayeux R, Mohs RC, Morris JC, Rossor MN, Scheltens P, Carrillo MC, Thies B, Weintraub S, Phelps CH: The diagnosis of dementia due to Alzheimer's disease: recommendations from the National Institute on Aging-Alzheimer's Association workgroups on diagnostic guidelines for Alzheimer's disease. Alzheimers Dement 2011, 7:263-269.

10. Soucy JP, Bartha R, Bocti C, Borrie M, Burhan AM, Laforce R Jr, Rosa-Neto P: Clinical applications of neuroimaging in patients with Alzheimer's disease: a review from the Fourth Canadian Consensus Conference on the Diagnosis and Treatment of Dementia 2012. Alzheimer's Research \& Therapy 2013, 5(Suppl 1):S3.

11. Burhan AM, Bartha R, Bocti C, Borrie M, Laforce R Jr, Rosa-Neto P, Soucy JP: Role of emerging neuroimaging modalities in patients with cognitive impairment: a review from the Canadian Consensus Conference on Dementia 2012. Alzheimer's Research \& Therapy 2013, 5(Suppl 1):S4.

12. Herrmann N, Lanctôt KL, Hogan DB: Pharmacological recommendations for the symptomatic treatment of dementia: the Canadian Consensus Conference on the Diagnosis and Treatment of Dementia 2012. Alzheimer's Research \& Therapy 2013, 5(Suppl 1):S5

\section{doi:10.1186/alzrt196}

Cite this article as: Patterson C, Gauthier S: Diagnosis and Treatment of Dementia: the Fourth Canadian Consensus Conference. Alzheimer's Research \& Therapy 2013, 5(Suppl 1):S1. 